\title{
FIRM SIZE AND DIVERSIFICATION: ASYMMETRIC MULTIPRODUCT FIRMS UNDER COURNOT COMPETITION
}

\author{
VOLKER GROSSMANN
}

CESIFO WORKING PAPER NO. 1047

CATEGORY 9: INDUSTRIAL ORGANISATION

SEPTEMBER 2003

An electronic version of the paper may be downloaded

- from the SSRN website:

www.SSRN.com

- from the CESifo website: www.CESifo.de 


\title{
FIRM SIZE AND DIVERSIFICATION: ASYMMETRIC MULTIPRODUCT FIRMS UNDER COURNOT COMPETITION
}

\begin{abstract}
A positive relationship between firm size and product diversification is a long-standing stylized fact. However, so far there is no appropriate theoretical model to explain the underlying forces of this observation. This paper analyzes an oligopoly model with asymmetric multiproduct frms, which is capable of addressing this issue. The model suggests that intangible assets of firms, which affect marginal costs or perceived quality of goods within a firm's product line, play a key role for the empirical regularity that larger firms are more diversified.
\end{abstract}

JEL Code: L11, L13.

Keywords : asymmetric equilibrium, diversification, firm size, intangible assets, multiproduct firms.

\author{
Volker Grossmann \\ Socioeconomic Institute \\ University of Zurich \\ Zürichbergstr. 14 \\ CH-8032 Zurich \\ Switzerland \\ volker.grossmann@wwi.unizh.ch
}

I am grateful to Armin Schmutzler and Josef Falkinger for detailed and valuable comments and suggestions on an earlier draft. I am also indebted to Simon Anderson and seminar participants at the University of Zurich for helpful discussions. 


\section{Introduction}

Product diversification is a dominant feature of firms in advanced countries. In particular, by using various indicators, empirical evidence for the manufacturing sector strongly suggests that there is a positive relationship between the size of firms/establishments and diversification, particularly regarding the number of products offered (e.g., Amey, 1964; Utton, 1977; Gollop and Monahan, 1991). ${ }^{1}$ However, so far there is no appropriate theoretical analysis in the literature to explain the underlying forces of this important empirical regularity. In fact, due to the analytical complexity of oligopoly models with multiproduct firms, existing multiproduct models have focussed on the analysis of symmetric firms. ${ }^{2}$ However, this modelling strategy does not allow to address the observed relationship between product diversification and firm size.

In contrast, this paper analyzes a simple multiproduct oligopoly model in which firms are asymmetric with respect to their production technology and consumers' valuation of varieties within a firm's product line. Firms produce differentiated goods, facing linear demand, and are engaged in a two-stage decision process. At stage 1 , firms choose the number of products offered to the market. At stage 2, they enter Cournot competition. ${ }^{3}$

The main contribution of the paper is twofold. First, it derives basic properties of profit functions of multiproduct firms for the widely-used linear-demand model with

\footnotetext{
${ }^{1}$ For the U.S., Gollop and Monahan (1991, p. 327) conclude that "[q]uite clearly, large enterprises are more diversified than small ones". Moreover, their evidence suggests that a similarly strong result also holds at the establishment-level. In a recent study on Taiwanese firms, Aw and Batra (1998, p. 313) suggest that "[t]he positive relation between firm size and product diversification typically found in developed countries is limited to large exporting firms".

${ }^{2}$ For a theoretical analysis of various aspects of multiproduct firms, see, e.g., Raubitschek (1987), Shaked and Sutton (1990), Anderson and de Palma (1992), Anderson et al. (1992, ch. 7), Sutton (1998, ch. 2), and Ottaviano and Thisse (1999).

${ }^{3}$ For a similar modelling strategy, see, e.g., Raubitschek (1987), Sutton (1998), Ottaviano and Thisse (1999).
} 
differentiated goods under Cournot competition, for given configurations of both the number of products and firm-specific characteristics (i.e., at stage 2 equilibrium). Second, from these properties, the analysis provides for the first time a rigorous theoretical explanation for the observation that size and product diversification of a firm are positively related. Both variables, firm size, measured by total sales of a firm, and its number of products are determined by firm-specific characteristics, i.e., by marginal costs and perceived quality of a firm's products. Thus, comparativestatic analysis suggests that intangible assets of firms, like basic organizational or technological knowledge (affecting marginal costs) as well as consumer loyalty or trademarks (affecting perceived quality of a firm's products), play a key role for the empirical regularity that larger firms offer more diversified product lines. ${ }^{4}$

As well-known, applicability of standard tools for comparative-static analysis is very limited in the presence of strategic interactions of more than two players (e.g., Takayama, 1985; Dixit, 1986; Vives, 1999). However, focussing on the duopoly case is not very satisfying, as extension to the case of many firms adds complex interactions which need to be addressed. Fortunately, the structure of the model allows to apply a tool for comparative-statics in games with strategic substitutes which has recently been developed by Athey and Schmutzler (2001). By doing so, it is possible to derive a positive relationship between size and diversification for the $I$-firm model. Moreover, contrary to the common practice of ignoring the integer problem regarding the number of products, comparative-static results derived in this paper do not hinge on the treatment of product ranges as continuous variables.

The paper is organized as follows. Section 2 presents the basic model. Section 3 proves existence of a (pure-strategy) equilibrium and provides comparative-static

\footnotetext{
${ }^{4}$ Notably, in an informal way, Gorecki (1975) has already discussed the role of intangible assets for diversification, pointing out that "findings suggest that specific assets of a technological nature formed the basis of much diversification" (p. 134). For other motives of corporate diversification, see, e.g., the literature review by Montgomery (1994). Aydemir and Schmutzler (2002) provide a formal model in which mergers between big and small firms are driven by the motive of big firms to expand their product space, among other reasons.
} 
results. Section 4 discusses the integer problem, allows for heterogeneity among firms also with respect to diversification costs, and briefly addresses the empirical regularity of an upward trend of corporate diversification in the last decades. Moreover, testable hypotheses emerging from the analysis are discussed in more detail. Section 5 provides concluding remarks. Some proofs are relegated to an appendix.

\section{The Basic Model}

Consider a market for differentiated goods with a finite set $\mathcal{I}=\{1, \ldots, I\}$ of firms, indexed by $i$. Let $\mathcal{N}_{i}$ be the set of goods produced by firm $i$, in (endogenous) number $N_{i}$, and let $\mathcal{K}$ be the set of all varieties in the market. For the sake of tractability (allowing for closed-form solutions) and its familiarity, the inverse demand function for variety $k \in \mathcal{K}$ has the simple linear form

$$
p_{k}=A_{k}-\beta x_{k}-\gamma \sum_{l \neq k} x_{l}
$$

$A_{k}>0, \beta>\gamma>0$, where $p_{k}$ and $x_{k}$ denote the price and quantity of product $k$, respectively. ${ }^{5}$ Moreover, marginal production costs of each variety $k$ are constant and denoted by $c_{k} \geq 0$. Let $\alpha_{k} \equiv A_{k}-c_{k}>0, k \in \mathcal{K}$. The parameter $\alpha_{k}$ summarizes the relationship between perceived quality of variety $k$, reflected by $A_{k}$, and unit production costs, $c_{k}$. It is assumed that for all varieties offered by the same multiproduct firm, this relationship is identical. Formally, this means the following.

A1. (Firm-specific characteristics). $\alpha_{k}=\alpha_{i}>0$ for all $k \in \mathcal{N}_{i}, i \in \mathcal{I}$.

Assumption A1 implies that there is a positive relationship between perceived quality and unit production costs for all varieties supplied by a single firm. Moreover,

\footnotetext{
${ }^{5}$ That is, there is a representative consumer with quasi-linear preferences which are reflected by the utility function $U=\sum_{k \in \mathcal{K}}\left(A_{k} x_{k}-(\beta / 2) x_{k}^{2}\right)-\gamma \sum_{k} \sum_{l<k} x_{k} x_{l}+Y$, where $Y$ is the quantity of the numeriare commodity. As a caveat, however, the linear demand model is not capable to address the notion that products offered by a single firm are closer substitutes for each other than for products sold by different firms (Anderson and de Palma, 1992).
} 
firms are characterized by a single index $\alpha_{i}$. For instance, the view of consumers regarding the quality of a firm's products is affected by the trademark associated with a product line. Firms may also differ in their organizational know-how or their internal human capital stock, affecting productivity and thus marginal costs. In other words, firms may differ in their intangible assets, which is reflected by differences in $\alpha_{i}$ in the model. ${ }^{6}$ Consequently, $\alpha_{i}$ is called quality of intangible assets of firm $i$. The $I$-tuple $\boldsymbol{\alpha}=\left(\alpha_{1}, \alpha_{2}, \ldots, \alpha_{I}\right)$ is called a configuration of intangible asset qualities.

There are two stages, with decisions at each stage made non-cooperatively and simultaneously. At stage 1, firms choose their number of products $N_{i}$ ("product range"). Let $C:[1, \bar{N}] \rightarrow \mathbb{R}_{+}$be an increasing, twice continuously differentiable and convex function, $\bar{N}<\infty$. $C\left(N_{i}\right)$ denote the costs of firm $i$ to introduce $N_{i} \in[1, \bar{N}]$ products in the market. (In section 4, choice sets at stage 1 are restricted to positive integers $\{1,2, \ldots, \bar{N}\}$.) For instance, these include costs for marketing or designing products. $^{7}$ The $I$-tuple $\mathbf{N}=\left(N_{1}, N_{2}, \ldots, N_{I}\right)$ is called a configuration of product ranges. At stage 2, firms enter Cournot competition. This timing of events follows some existing literature on multiproduct firms (e.g., Raubitschek, 1987; Sutton, 1998; Ottaviano and Thisse, 1999). However, in contrast to this literature, the present set up allows for asymmetry of firms ex ante.

\footnotetext{
${ }^{6}$ The argument that a superior production technology or consumer loyality applies to any variety a firm offers also fits well into the common notion in the literature on multinational enterprises that intangible assets are of public good nature from the perspective of a single firm (see, e.g., Caves, 1971; Markusen, 2002).

${ }^{7}$ Assuming convexity of $C(\cdot)$ does not deny that there are economies of scope (or "subadditive costs") in marketing, designing or manufacturing multiple products within a firm (see, e.g., Baumol, 1977). However, one may think of increasing (Coasian) bureaucracy costs of product proliferation as a counteracting force. In fact, all that is needed is that $C(\cdot)$ is not "too concave" in the relevant range. For instance, Anderson and de Palma (1992) and Ottaviano and Thisse (1999) consider the special case of $C(N)=g N, g>0$, which is included in the present analysis. Also restricting the choice set of firms at stage 1 to the closed interval $[1, \bar{N}]$, rather than to $[1, \infty$ ) (relevant for proving existence of equilibrium) serves a purely technical purpose, as $\bar{N}$ can be arbitrarily large.
} 


\section{Equilibrium Analysis}

In this section, the equilibrium of the model is derived by backwards induction. Moreover, it is examined whether there exists a systematic relationship between size and product diversification of a firm, and, if yes, what determines this relationship.

\subsection{Cournot Competition (Stage 2)}

First, consider the decision problem of firms at stage 2, for a given configuration $\mathbf{N}$. Taking output levels of rival firms as given, each firm $i \in \mathcal{I}$ solves

$$
\max _{x_{k} \geq 0, k \in \mathcal{N}_{i}} \pi_{i}=\sum_{k \in \mathcal{N}_{i}}\left(p_{k}-c_{k}\right) x_{k} \text { s.t. (1). }
$$

Observing $\alpha_{i}=A_{k}-c_{k}$ for all $k \in \mathcal{N}_{i}$, according to A1, the following first result is obtained.

Proposition 1. (Equilibrium at stage 2). Under A1. In an interior CournotNash equilibrium at stage 2, each firm $i \in \mathcal{I}$ produces output level $\tilde{x}_{k} \equiv \tilde{x}_{i}$ for all $k \in \mathcal{N}_{i}$ with

$$
\tilde{x}_{i}=\frac{\Lambda_{i}}{\left(1+\sum_{i} \Gamma_{i}\right)\left[2(\beta-\gamma)+\gamma N_{i}\right]} \equiv X_{i}(\mathbf{N}, \boldsymbol{\alpha})
$$

and earns profits

$$
\tilde{\pi}_{i}=N_{i}\left(\beta-\gamma+\gamma N_{i}\right) X_{i}(\mathbf{N}, \boldsymbol{\alpha})^{2} \equiv \Pi_{i}(\mathbf{N}, \boldsymbol{\alpha})
$$

where $\Gamma_{i} \equiv \gamma N_{i} /\left[2(\beta-\gamma)+\gamma N_{i}\right] \in(0,1)$ and $\Lambda_{i} \equiv \alpha_{i}\left(1+\sum_{j \neq i} \Gamma_{j}\right)-\sum_{j \neq i} \alpha_{j} \Gamma_{j}$.

Proof. See appendix.

The analysis focusses on configurations of intangible asset qualities, $\boldsymbol{\alpha}$, such that $\Lambda_{i}>0$, and thus, $\tilde{x}_{i}>0$ for all $i$. According to Proposition 1, a multi-product firm $i$ produces equal output levels for all varieties $k \in \mathcal{N}_{i}$ which it offers. This is due to the symmetry of varieties in demand schedules (1), together with assumption A1. Moreover, output levels of single products (i.e., sales per variety) of firm $i, \tilde{x}_{i}$, are 
positively related to the intangible asset quality $\alpha_{i}$, for any given configuration of product ranges $\mathbf{N}$.

Apart from own $\alpha_{i}$, output levels and profits of a firm $i$ depend on other firms' intangible asset qualities $\alpha_{j}, j \neq i$, and on configuration $\mathbf{N}$. The following corollaries characterize profit functions $\tilde{\pi}_{i}=\Pi_{i}(\mathbf{N}, \boldsymbol{\alpha})$ in equilibrium at stage 2 . In particular, these results will prove helpful for the comparative-static analysis of the next subsection, in which the firms' choice of product ranges (stage 1) is considered.

Corollary 1. (Properties of stage 2 profit functions). Consider the set of profit functions $\Pi_{i}:[1, \bar{N}]^{I} \times \mathbb{R}_{+}^{I} \rightarrow \mathbb{R}_{+}$, $i \in \mathcal{I}$. For all $i, j \in \mathcal{I}, j \neq i$, we have

(i) $\partial \Pi_{i}(\mathbf{N}, \boldsymbol{\alpha}) / \partial N_{i}>0$ and $\partial^{2} \Pi_{i}(\mathbf{N}, \boldsymbol{\alpha}) / \partial N_{i}^{2}<0$,

(ii) $\partial \Pi_{i}(\mathbf{N}, \boldsymbol{\alpha}) / \partial N_{j}<0$,

(iii) $\partial \Pi_{i}(\mathbf{N}, \boldsymbol{\alpha}) / \partial \alpha_{i}>0$ and $\partial \Pi_{i}(\mathbf{N}, \boldsymbol{\alpha}) / \partial \alpha_{j}<0$,

(iv) $\partial^{2} \Pi_{i}(\mathbf{N}, \boldsymbol{\alpha}) / \partial N_{i} \partial \alpha_{i}>0$ and $\partial^{2} \Pi_{i}(\mathbf{N}, \boldsymbol{\alpha}) / \partial N_{i} \partial \alpha_{j}<0$;

(v) if $\alpha_{i} \leq \alpha_{j}$ or if $\left(\alpha_{i}-\alpha_{j}\right)$ sufficiently small, then $\partial^{2} \Pi_{i}(\mathbf{N}, \boldsymbol{\alpha}) / \partial N_{i} \partial N_{j}<0$.

Proof. See appendix.

To gain insight into Corollary 1 , it is helpful to decompose $\Pi_{i}(\mathbf{N}, \boldsymbol{\alpha})$ into the product of total demand (or sales) of firm $i$ in equilibrium at stage $2, D_{i}(\mathbf{N}, \boldsymbol{\alpha}) \equiv$ $N_{i} X_{i}(\mathbf{N}, \boldsymbol{\alpha})$, and its price-cost difference ("mark-up"), $M_{i}(\mathbf{N}, \boldsymbol{\alpha}) \equiv\left(\beta-\gamma+\gamma N_{i}\right) X_{i}(\mathbf{N}, \boldsymbol{\alpha})$. That is, $\Pi_{i}(\mathbf{N}, \boldsymbol{\alpha})=D_{i}(\mathbf{N}, \boldsymbol{\alpha}) M_{i}(\mathbf{N}, \boldsymbol{\alpha})$, implying

$$
\begin{aligned}
\frac{\partial \Pi_{i}}{\partial N_{j}} & =\frac{\partial D_{i}}{\partial N_{j}} M_{i}+D_{i} \frac{\partial M_{i}}{\partial N_{j}}, \\
\frac{\partial^{2} \Pi_{i}}{\partial N_{j} \partial N_{i}} & =\frac{\partial^{2} D_{i}}{\partial N_{j} \partial N_{i}} M_{i}+\frac{\partial D_{i}}{\partial N_{j}} \frac{\partial M_{i}}{\partial N_{i}}+\frac{\partial D_{i}}{\partial N_{i}} \frac{\partial M_{i}}{\partial N_{j}}+D_{i} \frac{\partial^{2} M_{i}}{\partial N_{j} \partial N_{i}} .
\end{aligned}
$$

$i, j \in \mathcal{I}$. Total sales $D_{i}$ of a firm are used as measure of firm size for the discussion of results below. The properties of the functions $D_{i}(\mathbf{N}, \boldsymbol{\alpha})$ and $M_{i}(\mathbf{N}, \boldsymbol{\alpha})$, which are used in the following discussion of Corollary 1, are formally derived in an appendix available from the author upon request.

First, according to part (i) of Corollary 1, the impact of an increase in product range $N_{i}$ on both equilibrium demand, $D_{i}$, and on equilibrium mark-up, $M_{i}$, is 
positive. ${ }^{8}$ Thus, $\partial \Pi_{i} / \partial N_{i}>0$, according to (5) (for $i=j$ ), whenever varieties are imperfect substitutes (i.e., $\beta>\gamma) .{ }^{9}$ Moreover, strict concavity of profits at stage $2, \Pi_{i}$, as function of product range $N_{i}$ means that a firm's incentive to launch new varieties is weaker, the more diversified the firm is. Using (6) (for $i=j$ ) and the definitions of $D_{i}$ and $M_{i}$, one can show that the underlying reason for this result is that the marginal gain of an increase in $N_{i}$ regarding both $D_{i}$ and $M_{i}$ is decreasing, i.e., $\partial^{2} D_{i} / \partial N_{i}^{2}<0$ and $\partial^{2} M_{i} / \partial N_{i}^{2}<0$.

Part (ii) of Corollary 1 means that a firm's profits at stage $2, \tilde{\pi}_{i}$, decline if any rival offers additional products, which reflects a conventional "business-stealing effect". In fact, an increase in $N_{j}$ reduces both $D_{i}$ and $M_{i}$ of a firm $i \neq j$. Also unsurprisingly, part (iii) says that $\tilde{\pi}_{i}$ increases with its own intangible asset quality, $\alpha_{i}$, but decreases with other firms' intangible asset qualities, $\alpha_{j}, j \neq i$, holding the configuration of product ranges $\mathbf{N}$ constant. Again, the effects regarding both $D_{i}$ and $M_{i}$ go in the same direction.

According to part (iv), the profit gain of firm $i$ from introducing additional varieties increases with $\alpha_{i}$, but decreases with the strength of rivals $\alpha_{j}, j \neq i$, all other things equal. It is easy to confirm that an increase in $\alpha_{i}$ raises the impact of an increase in product range $N_{i}$ on both equilibrium demand $D_{i}$ and on equilibrium

\footnotetext{
${ }^{8}$ The latter effect may be somewhat surprising at the first glance, but can easily understood as follows. Note that (1), together with A1, implies that, in stage 2 equilibrium, $p_{k}-c_{k}=$ $\alpha_{i}-(\beta-\gamma) \tilde{x}_{i}-\gamma \tilde{Q} \equiv M_{i}$ for all $k \in \mathcal{N}_{i}, i \in \mathcal{I}$, where $\tilde{Q} \equiv \sum_{l \in \mathcal{K}} \tilde{x}_{l}$ is total equilibrium output in the market in stage 2 equilibrium. On the one hand, it is easy to check that an increase in $N_{i}$ raises $\tilde{Q}$, all other things equal (see appendix). This has a negative effect on $M_{i}$. On the other hand, however, firm $i$ reduces equilibrium output per variety, $\tilde{x}_{i}$, when increasing $N_{i}$, which has a positive effect on $M_{i}$. The second effect dominates the first one.

${ }^{9}$ Under the linear-demand structure (1), it is common to interpret the ratio $\beta / \gamma$ as the degree of substitution between goods. Note that for $\gamma \rightarrow \beta$, i.e., if varieties are perfect substitutes, the limiting profit function of a firm $i$ at stage 2 is given by $\lim _{\gamma \rightarrow \beta} \tilde{\pi}_{i}=\left[\left(I \alpha_{i}-\sum_{j \neq i} \alpha_{j}\right) /(1+I)\right]^{2} / \gamma$, according to (3) and (4). Obviously, it does not pay for firms to supply more than one variety in this limit case. In contrast, with imperfect substitutes, i.e., if $\beta>\gamma$, it may be optimal for firms to introduce more than one variety into the market, as will become apparent below.
} 
mark-up $M_{i}$ (i.e., $\partial^{2} D_{i} / \partial N_{i} \partial \alpha_{i}>0$ and $\left.\partial^{2} M_{i} / \partial N_{i} \partial \alpha_{i}>0\right)$, whereas an increase in $\alpha_{j}, j \neq i$, has the opposite effect on $\partial D_{i} / \partial N_{i}$ and $\partial M_{i} / \partial N_{i}$, respectively.

As will become apparent below, the impact of an increase in a rival's product range $N_{j}$ on the incentive of a firm $i \neq j$ to launch new varieties (i.e., how $\partial \prod_{i} / \partial N_{i}$ changes with $N_{j}, j \neq i$ ) is of particular importance for the subsequent analysis. From the previous discussion of parts (i) and (ii), for $j \neq i$, one can conclude that the second and third summand of the right-hand side of (6) are both negative. However, one can also show that the first and last summand have ambiguous sign, i.e., an increase in $N_{j}$ may increase or decrease both effects $\partial D_{i} / \partial N_{i}$ and $\partial M_{i} / \partial N_{i}$, $j \neq i$. Part ( $\mathrm{v}$ ) of Corollary 1 says that the profit gain of a firm $i$ from increasing product diversification is reduced by an increase in a rival's product range $N_{j}, j \neq i$, if $\alpha_{i} \leq \alpha_{j}$ or if $\left(\alpha_{i}-\alpha_{j}\right)$ is sufficiently small, i.e., whenever firms are not "too heterogeneous" with respect to their quality of intangible assets. As will become apparent, in this case, the optimal response at stage 1 to an increase in a rival's product number is to decrease the own number of varieties, i.e., product ranges of firms are strategic substitutes. The subsequent analysis exclusively focusses on this case.

A2. (Strategic substitutes). For all $i, j \in \mathcal{I}, j \neq i$, let $\partial^{2} \Pi_{i}(\mathbf{N}, \boldsymbol{\alpha}) / \partial N_{i} \partial N_{j}<0$.

It can be shown that, for some configurations $\mathbf{N}$, assumption A2 holds for all configurations $\boldsymbol{\alpha}$, i.e., even if firms are very heterogeneous. (See Remark 1 in appendix for a sufficient condition.)

Proposition 1 also implies the following useful result.

Corollary 2. (Exchangeability). Under A1. Let $(\hat{\mathbf{N}}, \hat{\boldsymbol{\alpha}})$ be a permutation of $(\mathbf{N}, \boldsymbol{\alpha})$ so that, for any pair $i, j \in \mathcal{I}, j \neq i,\left(\hat{N}_{i}, \hat{\alpha}_{i}\right)=\left(N_{j}, \alpha_{j}\right),\left(\hat{N}_{j}, \hat{\alpha}_{j}\right)=\left(N_{i}, \alpha_{i}\right)$ and $\left(\hat{N}_{h}, \hat{\alpha}_{h}\right)=\left(N_{h}, \alpha_{h}\right)$ for all $h \in \mathcal{I} \backslash\{i, j\}$. Then, we have $\Pi_{i}(\hat{\mathbf{N}}, \hat{\boldsymbol{\alpha}})=\Pi_{j}(\mathbf{N}, \boldsymbol{\alpha})$ and $\Pi_{h}(\hat{\mathbf{N}}, \hat{\boldsymbol{\alpha}})=\Pi_{h}(\mathbf{N}, \boldsymbol{\alpha})$ for all $h \in \mathcal{I} \backslash\{i, j\}$.

Corollary 2 is directly implied by the fact that profits at stage 2 are exclusively 
determined by configurations $\mathbf{N}$ and $\boldsymbol{\alpha}$. Thus, exchanging both intangible asset qualities and product ranges of two firms also leads to an exchange of these firms' profits at stage 2, without affecting other firms' profits. Following Athey and Schmutzler (2001) (AS hereafter), we say that profit functions $\Pi_{i}$ are "exchangeable" as functions of $(\mathbf{N}, \boldsymbol{\alpha})$. Exchangeability also plays a crucial role for the comparative-statics of the $I$-player case below.

\subsection{Firms' Choice of Number of Products (Stage 1)}

By analyzing the firms' choice of number of products (stage 1), this subsection characterizes the equilibrium configuration of product ranges, denoted $\mathbf{N}^{*}$, given the configuration of intangible asset qualities, $\boldsymbol{\alpha}$.

Given $\boldsymbol{\alpha}$, the profit maximization problem for each firm $i \in \mathcal{I}$ at stage 1 is to solve

$$
\max _{N_{i} \in[1, \bar{N}]} \Psi_{i}(\mathbf{N}, \boldsymbol{\alpha}) \equiv \Pi_{i}(\mathbf{N}, \boldsymbol{\alpha})-C\left(N_{i}\right) .
$$

Strategic interactions of firms at stage 1 are represented by the game $\left\{\left([1, \bar{N}], \Psi_{i}\right), i \in \mathcal{I}\right\}$. Concavity of stage 2 profits, $\Pi_{i}$, as function of $N_{i}$ (part (i) of Corollary 1) ensures existence of equilibrium.

Proposition 2. (Existence of equilibrium). Under A1. For any given $\boldsymbol{\alpha} \in \mathbb{R}_{+}^{I}$, a pure-strategy Nash equilibrium of the game $\left.\left\{\left([1, \bar{N}], \Psi_{i}\right), i \in \mathcal{I}\right\}\right)$ exists. Thus, a subgame-perfect equilibrium of the two-stage game exists.

Proof. See appendix.

Let $N_{i}^{*}(\boldsymbol{\alpha})$ be an equilibrium product range offered by firm $i \in \mathcal{I}$. Without loss of generality (as $\bar{N}$ can be arbitrarily large), the analysis focusses on $N_{i}^{*}<\bar{N}$ for all $i$. Using (7), an equilibrium configuration of product ranges $\mathbf{N}^{*}=\left(N_{1}^{*}, \ldots, N_{I}^{*}\right)$ is then given by the following set of first-order conditions:

$$
\frac{\partial \Pi_{i}\left(\mathbf{N}^{*}, \boldsymbol{\alpha}\right)}{\partial N_{i}} \leq C^{\prime}\left(N_{i}^{*}\right), i \in \mathcal{I}
$$

with strict equality if $N_{i}^{*}>1$. 


\subsubsection{The Duopoly Case}

We are now ready to address the question how differences in equilibrium product ranges, $N_{i}^{*}$, among firms (i.e., equilibrium diversification) depend on differences in intangible asset qualities, $\alpha_{i}$. First, consider the duopoly case, $I=2$.

Proposition 3. (Product range in duopoly). Under A1 and A2. If $\mathcal{I}=\{1,2\}$ and the equilibrium is unique, then $\alpha_{i}>\alpha_{j}$ implies $N_{i}^{*}(\boldsymbol{\alpha})>N_{j}^{*}(\boldsymbol{\alpha})$.

As will become apparent below, Proposition 3 is a special case of Proposition 4 . Therefore, no formal proof of the two-player case is provided. Rather, the result is illustrated graphically in Fig. 1. Note from (8) and strict concavity of $\Psi_{i}(\mathbf{N}, \boldsymbol{\alpha})$ as function of $N_{i}$ that reaction functions are downward sloping under A2, i.e., $N_{1}$ and $N_{2}$ are strategic substitutes. Uniqueness of equilibrium requires that the reaction function of firm 1 is steeper than that of firm 2. ${ }^{10}$ According to part (iv) of Corollary 1 , an increase in, say, $\alpha_{1}$ shifts the reaction function of firm 1 rightward and that of firm 2 downward, as shown in Fig. 1. That is, the marginal gain of firm 1 to extend its product range increases and the marginal gain of firm 2 decreases.

\section{$<$ Please insert Figure 1 about here $>$}

Fig. 1 depicts two kinds of a unique equilibrium (observing restriction $N_{i} \geq 1$, $i \in \mathcal{I}$ ). In panel (a), the equilibrium is interior, whereas $N_{2}^{*}=1$ in panel (b). In panel (a), an increase in $\alpha_{1}$ leads to an increase in $N_{1}^{*}$ and a decrease in $N_{2}^{*} \cdot{ }^{11}$ In

\footnotetext{
${ }^{10}$ Note that any unique equilibrium is also "stable" if reaction functions are interpreted as describing dynamic behavior with alternate-period decisions. Using (8), it is easy to check that the reaction function of firm 1 is stepper than that of firm 2 if

$$
\left(\left|\frac{\partial^{2} \Pi_{1}}{\partial N_{1}^{2}}\right|+C^{\prime \prime}\left(N_{1}\right)\right)\left(\left|\frac{\partial^{2} \Pi_{2}}{\partial N_{2}^{2}}\right|+C^{\prime \prime}\left(N_{2}\right)\right)>\left|\frac{\partial^{2} \Pi_{1}(\mathbf{N}, \boldsymbol{\alpha})}{\partial N_{1} \partial N_{2}}\right|\left|\frac{\partial^{2} \Pi_{1}(\mathbf{N}, \boldsymbol{\alpha})}{\partial N_{1} \partial N_{2}}\right| .
$$

${ }^{11}$ In contrast, if the reaction function of firm 2 in $N_{1}-N_{2}$ space is steeper than that of firm 1 (implying multiple equilibria), it is easy to check that for an interior equilibrium the opposite holds. See below for more discussion on the uniqueness requirement.
} 


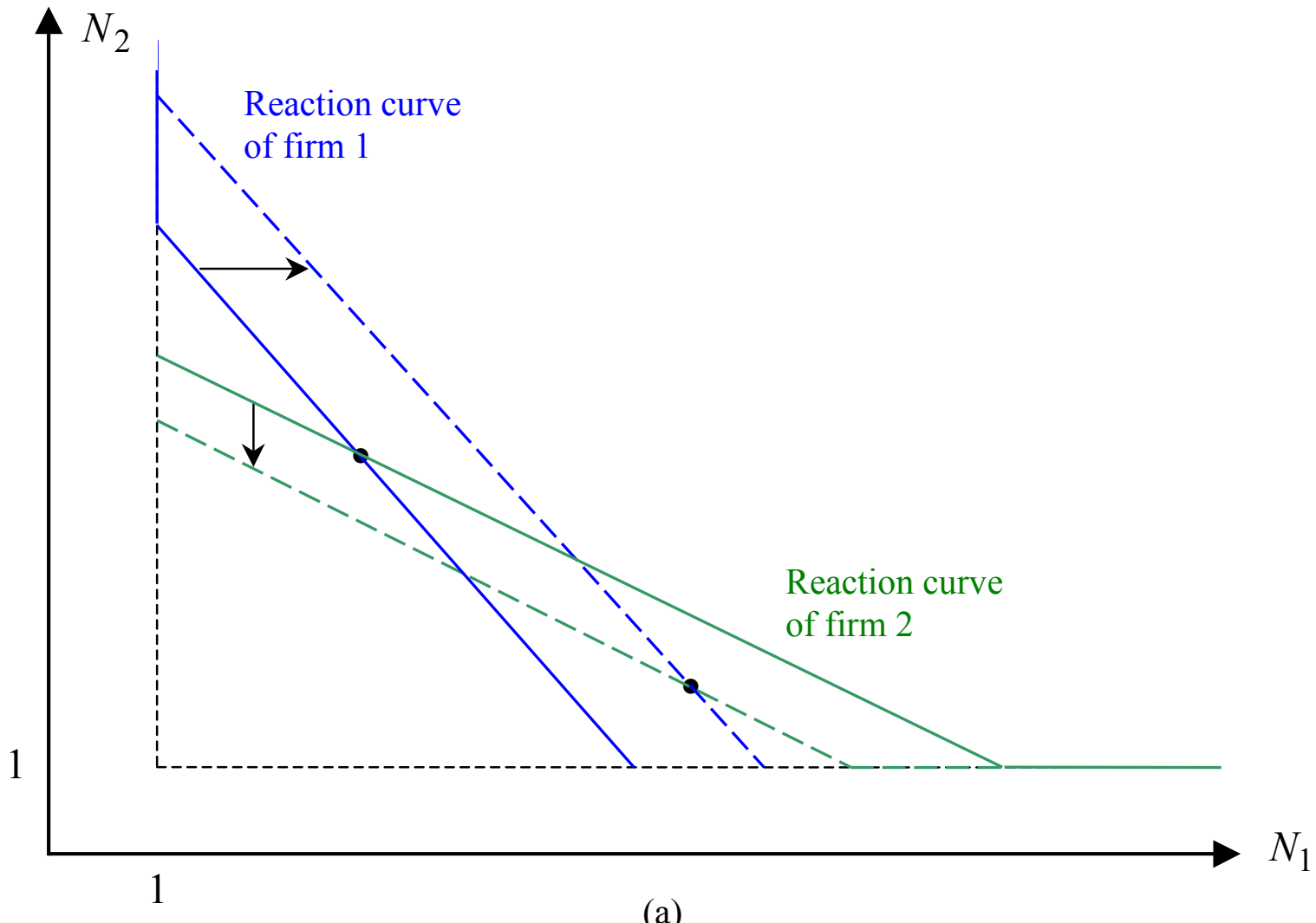

(a)

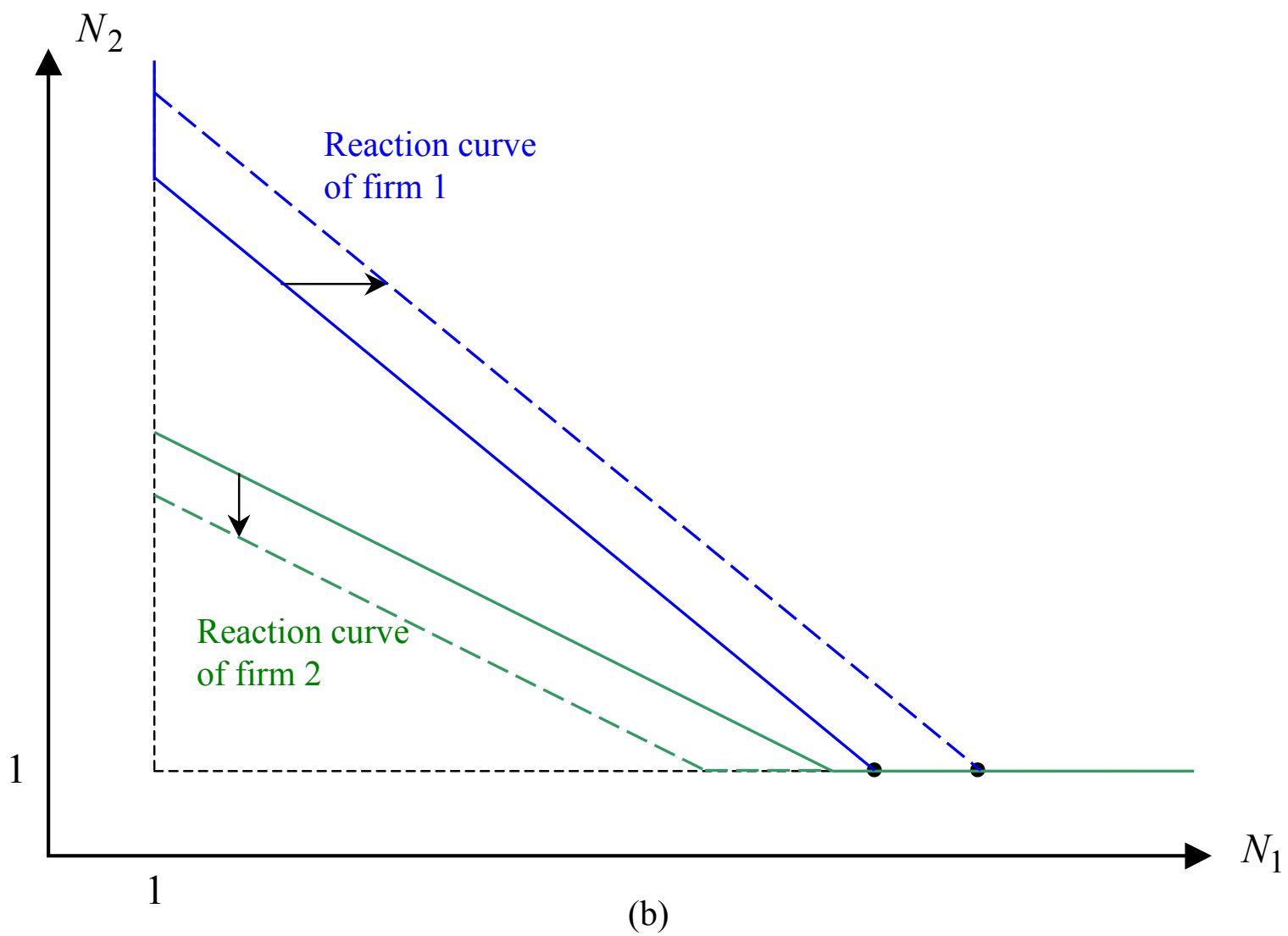

Figure 1: The impact of an increase in $\alpha_{1}$ on $N_{1}^{*}$ and $N_{2}^{*}$ in the duopoly case. 
panel (b), only $N_{1}^{*}$ increases. $^{12}$

\subsubsection{The Case $I>2$}

In view of the duopoly case, it seems intuitive that firms with higher intangible asset qualities have more diversified product lines. However, as it is well-known from oligopoly theory, in general, comparative-static analysis of asymmetric equilibria with more than two players can be very messy and may require strong assumptions (e.g., Takayama, 1985; Dixit, 1986; Vives, 1999). To see the economic reason for this in the present context, consider, again, an increase in $\alpha_{1}$. Recall that, in response to an increase in $\alpha_{1}$, firm 1 has an incentive to increase $N_{1}$ and firm 2 has an incentive to decrease $N_{2}$. On the one hand, if product ranges are strategic substitutes, an actual rise in $N_{1}$ would have a negative impact on the marginal gain of a firm 3 (or higher) of increasing its product range. However, an actual decrease of $N_{2}$ would have the opposite effect on the behavior of firm 3. A priori, it is not clear which effect dominates. In fact, an analogous argument holds for firm 2 as well. If firm 3 decreases $N_{3}$ in response to an increase in $\alpha_{1}$, firm 2 has an incentive to increase $N_{2}$. This even leaves the behavioral response of firm 1 ambiguous. Due to these complexities, generalization of the comparative-static results from the duopoly case to the case $I>2$ is not straightforward.

Moreover, multiplicity of equilibria may create problems for comparative-static analysis. To ensure uniqueness of equilibrium, one could invoke standard "dominantdiagonal" conditions (see, e.g., Vives, 1999). In the present analysis,

$$
\left|\frac{\partial^{2} \Pi_{i}(\mathbf{N}, \boldsymbol{\alpha})}{\partial N_{i}^{2}}\right|>\sum_{j \neq i}\left|\frac{\partial^{2} \Pi_{i}(\mathbf{N}, \boldsymbol{\alpha})}{\partial N_{i} \partial N_{j}}\right| \text { for all } i \in \mathcal{I},
$$

would be sufficient. However, (9) may be a strong assumption if the number of players is high. Rather, following AS, it is assumed that the set of equilibrium strategies at stage 1 satisfies "conditional uniqueness". Formally, this means the following.

\footnotetext{
${ }^{12}$ Qualitatively, a decrease in $\alpha_{2}$ has the same effects as an increase in $\alpha_{1}$.
} 
A3. (Conditional uniqueness). For each $i, j \in \mathcal{I}$ and each $\boldsymbol{\alpha} \in \mathbb{R}_{+}^{I}$, if there exist two equilibrium configurations of product ranges $\mathbf{N}^{*}(\boldsymbol{\alpha})$ and $\mathbf{N}^{* *}(\boldsymbol{\alpha})$ which fulfill $N_{h}^{*}(\boldsymbol{\alpha})=N_{h}^{* *}(\boldsymbol{\alpha})$ for all $h \in \mathcal{I} \backslash\{i, j\}$, then $N_{i}^{*}(\boldsymbol{\alpha})=N_{i}^{* *}(\boldsymbol{\alpha})$ and $N_{j}^{*}(\boldsymbol{\alpha})=N_{j}^{* *}(\boldsymbol{\alpha})$.

For $I=2$, conditional uniqueness reduces to uniqueness of equilibrium. However, if $I>2$, the requirement of conditional uniqueness is considerably weaker. For instance, as argued in AS, a sufficient condition for conditional uniqueness of equilibria is

$$
\left|\frac{\partial^{2} \Pi_{i}(\mathbf{N}, \boldsymbol{\alpha})}{\partial N_{i}^{2}}\right|>\left|\frac{\partial^{2} \Pi_{i}(\mathbf{N}, \boldsymbol{\alpha})}{\partial N_{i} \partial N_{j}}\right| \text { for all } i, j \in \mathcal{I}, j \neq i .
$$

In the present context, condition (10) is a fairly weak requirement, as can be seen from the expressions for $\partial^{2} \Pi_{i}(\mathbf{N}, \boldsymbol{\alpha}) / \partial N_{i}^{2}$ and $\partial^{2} \Pi_{i}(\mathbf{N}, \boldsymbol{\alpha}) / \partial N_{i} \partial N_{j}, j \neq i$, in appendix.

We are now ready to analyze comparative-statics for the $I$-player case. The next result is derived by applying a recent tool for comparative-static analysis of games with strategic substitutes, due to AS.

Proposition 4. (Product range in I-player case). Under A1-A3. For all $i, j \in \mathcal{I}$, if $\alpha_{i}>\alpha_{j}$ then $N_{i}^{*}(\boldsymbol{\alpha})>N_{j}^{*}(\boldsymbol{\alpha})$.

Proof. Let $\mathbf{N}_{-i}$ denote $\left(N_{1}, \ldots, N_{i-1}, N_{i+1}, \ldots, N_{I}\right)$ and write $\mathbf{N}=\left(N_{i}, \mathbf{N}_{-i}\right)$. Now consider the following definition.

Definition 1. (E.g., Vives, 1999). $\Psi_{i}\left(N_{i}, \mathbf{N}_{-i}, \boldsymbol{\alpha}\right)$ has (strictly) increasing differences in $\left(N_{i}, \alpha_{j}\right)$ if, for all $N_{i}>N_{i}^{\prime}, \Psi_{i}\left(N_{i}, \mathbf{N}_{-i}, \boldsymbol{\alpha}\right)-\Psi_{i}\left(N_{i}^{\prime}, \mathbf{N}_{-i}, \boldsymbol{\alpha}\right)$ is (strictly) increasing in $\alpha_{j}, i, j \in \mathcal{I}$; (strictly) decreasing differences are defined replacing "increasing" by "decreasing".

If $\Psi_{i}(\mathbf{N}, \boldsymbol{\alpha})$ is smooth and $\partial^{2} \Psi_{i}(\mathbf{N}, \boldsymbol{\alpha}) / \partial N_{i} \partial \alpha_{j}>0$, then $\Psi_{i}(\mathbf{N}, \boldsymbol{\alpha})$ has strictly increasing differences in $\left(N_{i}, \alpha_{j}\right)$. (See, e.g., Vives, 1999). As a next step, note that the following holds.

Lemma 1. (Athey and Schmutzler, 2001). Let $N_{i} \in S_{i}$ be a one-dimensional choice variable for player $i \in \mathcal{I}$. Suppose the set of equilibria of the game $\left\{\left(S_{i}, \Psi_{i}\right), i \in \mathcal{I}\right\}$ 
is non-empty and fulfills conditional uniqueness. Suppose further that (i) the players' choices are strategic substitutes, (ii) $\Psi_{i}(\mathbf{N}, \boldsymbol{\alpha})$ is exchangeable in $(\mathbf{N}, \boldsymbol{\alpha})$, and (iii) for all $i, j \in \mathcal{I}, j \neq i, \Psi_{i}(\mathbf{N}, \boldsymbol{\alpha})$ has increasing differences in $\left(N_{i}, \alpha_{i}\right)$ and decreasing differences in $\left(N_{i}, \alpha_{j}\right)$. Let $\mathbf{N}^{*}$ be an equilibrium configuration. Then $\alpha_{i}>\alpha_{j}$ implies $N_{i}^{*}(\boldsymbol{\alpha}) \geq N_{j}^{*}(\boldsymbol{\alpha})$.

In the present context, an equilibrium exists, according to Proposition 2, and the set of equilibria fulfills conditional uniqueness by assumption A3. It is now argued that conditions (i)-(iii) of Lemma 1 hold. Recalling $\Psi_{i}(\mathbf{N}, \boldsymbol{\alpha})=\Pi_{i}(\mathbf{N}, \boldsymbol{\alpha})-$ $C\left(N_{i}\right)$, condition (i) holds by A2. Condition (ii) of Lemma 1 follows from Corollary 2, applying the same definition of "exchangeability" as in AS. Finally, note that $\partial^{2} \Psi_{i}(\mathbf{N}, \boldsymbol{\alpha}) / \partial N_{i} \partial \alpha_{i}>0$ and $\partial^{2} \Psi_{i}(\mathbf{N}, \boldsymbol{\alpha}) / \partial N_{i} \partial \alpha_{j}<0, j \neq i$, according to part (iv) of Corollary 1. Thus, also condition (iii) of Lemma 1 is fulfilled. Hence, $\alpha_{i}>\alpha_{j}$ implies $N_{i}^{*}(\alpha) \geq N_{j}^{*}(\alpha)$, according to Lemma 1 .

However, in order to prove that $\alpha_{i}>\alpha_{j}$ indeed implies $N_{i}^{*}(\boldsymbol{\alpha})>N_{j}^{*}(\boldsymbol{\alpha})$ (i.e., firm $i$ has a strictly larger product range than firm $j$ ), Lemma 1 has to be modified slightly. In fact, the following can be deducted from the analysis of AS in a straightforward way.

Lemma 2. Presume the same as in Lemma 1. Suppose further that $\Psi_{i}(\mathbf{N}, \boldsymbol{\alpha})$ is smooth and for all $i, j \in \mathcal{I}, j \neq i, \partial^{2} \Psi_{i}(\mathbf{N}, \boldsymbol{\alpha}) / \partial N_{i} \partial \alpha_{i}>0$ and $\partial^{2} \Psi_{i}(\mathbf{N}, \boldsymbol{\alpha}) / \partial N_{i} \partial \alpha_{j}<$ 0. Then $\alpha_{i}>\alpha_{j}$ implies $N_{i}^{*}(\boldsymbol{\alpha})>N_{j}^{*}(\boldsymbol{\alpha})$.

As $\Psi_{i}(\mathbf{N}, \boldsymbol{\alpha})$ are smooth and, as argued above, also all other presumptions of Lemma 2 hold, Proposition 4 is confirmed.

According to Proposition 4, the comparative-statics from the duopoly case carry over to the case $I>2$. This is rather surprising in view of the complex additional interactions among firms (as outlined above) when there are more than two firms. One reason is that firms are symmetric in the sense that, ex ante, firms can be characterized by their intangible asset quality, $\alpha_{i}$, only (recall the exchangeability property in Corollary 2). For instance, it does not matter for firm 3 (and higher) if 
firm 1 has $\alpha_{1}$ and firm 2 has $\alpha_{2}$ or if firm 1 has $\alpha_{2}$ and firm 2 has $\alpha_{1}$. As argued by AS (p. 10), such a situation allows "to hold fixed the behavior of players 3 and higher and focus on a two-player game". The preceding analysis has used this argument to examine the behavior of asymmetric multiproduct firms in the linear-demand Cournot model regarding the choice of the number of products.

\subsection{Firm Size and Diversification}

We are now ready to derive the relationship between firm size and equilibrium diversification. Equilibrium firm size is measured by total sales of a firm in equilibrium, i.e., by equilibrium demand $D_{i}^{*}(\boldsymbol{\alpha}) \equiv D_{i}\left(\mathbf{N}^{*}, \boldsymbol{\alpha}\right), i \in \mathcal{I}$. By making use of Proposition 4 , one can show the following.

Proposition 5. (Firm size). Under A1-A3. For all $i, j \in \mathcal{I}$, if $\alpha_{i}>\alpha_{j}$ then $D_{i}^{*}(\boldsymbol{\alpha})>D_{j}^{*}(\boldsymbol{\alpha})$.

Proof. See appendix.

As a corollary of Propositions 4 and 5, the following theorem emerges.

Theorem 1. (Firm size and diversification). Under A1-A3. Firm size, measured by total equilibrium sales, and product diversification are positively related. The underlying determinant of both variables is the quality of intangible assets of a firm.

Testable hypotheses implied by Theorem 1 as well as some modifications of the analysis are discussed in the next section.

\section{Discussion}

\subsection{Testable Hypotheses}

According to the preceding analysis, heterogeneity of firms in marginal production costs or perceived quality of goods within product lines account for differences of 
firms in both total sales (i.e., firm size) and product diversification. This suggests that intangible assets of firms are a key to understand the long-standing stylized fact of a positive size-diversification relationship (Theorem 1).

Interestingly, as far as differences in marginal production costs among firms are concerned, empirical evidence is also consistent with Proposition 5. For instance, Roberts and Supina (2000) report a negative correlation between firm size and marginal costs among U.S. manufacturing firms. Moreover, using micro-level data from the 'Longitudinal Research Database' (developed by the U.S. Bureau of the Census), Baily et al. (1992) find that the size of U.S. manufacturing firms is positively related to total factor productivity (see their Tab. 8 and 9). However, whereas in this literature productivity is the dependent variable in regression analysis, the theory developed in this paper suggests that productivity jointly determines both size and diversification. ${ }^{13}$

Moreover, the analysis suggests that consumer loyalty, which may be determined and thus proxied by past advertising effort, is not only related to sales of a firm but also to its product diversification. However, as pointed out by Gorecki (1975, footnote 16), one has to distinguish between advertising on brand names of single products and advertising which, in addition, refers to the name (or trademark) of an enterprise (as, e.g., in the automobile industry). Only the latter kind of advertising affects consumers' views on other products supplied by a firm, and thus, is related to consumers' valuation of a firms' trademark.

\subsection{The Integer Problem}

Existence of a pure-strategy equilibrium (Proposition 2) is ensured by the continuous choice sets at stage $1,[1, \bar{N}]$. Obviously, however, the common practice in the theoretical literature on multiproduct firms of treating the $N_{i}$ 's as continuous variables is

\footnotetext{
${ }^{13}$ In fact, Baily et al. (1992, p. 223) carefully point out that their results should not be interpreted as causal effects but rather reflect correlations. See Bartelsman and Doms (2000) for an excellent survey of the empirical literature on productivity differences among firms.
} 
problematic. Fortunately, in the present context, comparative-static analysis is also possible when choice sets at stage 1 are restricted to positive integers $\{1,2, \ldots, \bar{N}\}$. (That is, differentiability of profits $\Psi_{i}(\mathbf{N}, \boldsymbol{\alpha})$ is not required.) However, there is an important caveat. Although every finite normal form game has at least one Nash equilibrium, existence of a pure-strategy equilibrium may not be guaranteed in the present context. If it exists, the following can be stated.

Proposition 6. (Integer choice sets). Under A1-A3. Let strategy sets of firms at stage 1 be given by $S_{i} \equiv\{1,2, \ldots, \bar{N}\}, i \in \mathcal{I}$. Suppose that a pure-strategy equilibrium for the game $\left\{\left(S_{i}, \Psi_{i}\right), i \in \mathcal{I}\right\}$ exists. Then, $\alpha_{i}>\alpha_{j}$ implies both $N_{i}^{*}(\boldsymbol{\alpha}) \geq N_{j}^{*}(\boldsymbol{\alpha})$ and $D_{i}^{*}(\boldsymbol{\alpha})>D_{j}^{*}(\boldsymbol{\alpha})$. Thus, if anything, larger firms are more diversified.

Proof. Note that Definition 1 and Lemma 1 (see the proof of Proposition 4) do not rely on differentiability of $\Psi_{i}(\mathbf{N}, \boldsymbol{\alpha}), i \in \mathcal{I}$. Thus, the result that $\alpha_{i}>\alpha_{j}$ implies $N_{i}^{*}(\boldsymbol{\alpha}) \geq N_{j}^{*}(\boldsymbol{\alpha})$ directly follows from Lemma 1, as it has already been established that all presumptions of Lemma 1 hold. Moreover, using $N_{i}^{*} \geq N_{j}^{*}$, the result that $\alpha_{i}>\alpha_{j}$ implies $D_{i}^{*}(\boldsymbol{\alpha})>D_{j}^{*}(\boldsymbol{\alpha})$ can directly be deducted from the proof of Proposition 5. This concludes the proof.

With choice sets at stage 1 being restricted to positive integers, it is now possible that $N_{i}^{*}=N_{j}^{*}$ if $\alpha_{i}>\alpha_{j}$. Moreover, note that even in this case total sales of firm $i$ are strictly larger than those of firm $j$, i.e., $D_{i}^{*}>D_{j}^{*}$ if $\alpha_{i}>\alpha_{j}$.

\subsection{Heterogeneity in Diversification Costs}

In the preceding analysis, the sunk cost schedule at stage $1, C(\cdot)$, for introducing products in the market is identical among firms. This is a strong assumption. For instance, firms with higher perceived product quality may have lower marketing costs to introduce new varieties in the market, e.g., if their trademark is well recognized. Moreover, firms with low marginal production costs may be more efficient also in introducing additional products to the market, i.e., in marginal costs of designing or marketing. In order to capture these possibilities, replace $C\left(N_{i}\right)$ by $K\left(N_{i}, \alpha_{i}\right)$, 
assuming that $\partial^{2} K\left(N_{i}, \alpha_{i}\right) / \partial N_{i} \partial \alpha_{i} \leq 0$. In this case, Proposition 4 remains valid, as implied by its proof. (Thus, both Proposition 5 and Theorem 1 still hold.) The same is true even if $\partial^{2} K\left(N_{i}, \alpha_{i}\right) / \partial N_{i} \partial \alpha_{i}>0$, as long as $\partial^{2} \Pi_{i}(\mathbf{N}, \boldsymbol{\alpha}) / \partial N_{i} \partial \alpha_{i} \geq$ $\partial^{2} K\left(N_{i}, \alpha_{i}\right) / \partial N_{i} \partial \alpha_{i}$

\subsection{Increasing Average Diversification}

The main focus in this paper is the role of intangible assets for explaining crosssection evidence regarding the relationship between firm size and product diversification. This subsection briefly discusses another empirical regularity, namely a steady upward trend in product diversification of firms in the last decades. For instance, Goto (1981) presents evidence from large Japanese firms in various industries between 1963 and 1975 which suggests that firms became considerably more diversified with respect to their commodities over time. Gollop and Monahan (1991) analyze data from manufacturing firms for five points in time in the period between 1963 and 1982, concluding that "[d]iversification has replaced horizontal growth" (p. 318). In more recent times, the emergence of computer-aided design (CAD) has reduced costs of product design and development. Moreover, computer-aided manufacturing (CAM) has reduced production costs. As argued by Milgrom and Roberts (1990), these developments have increased the firms' incentives to extend product lines.

It is straightforward to capture these trends in the present context. As asymmetry of firms is not crucial for these arguments, for simplicity, suppose $\alpha_{i}=\hat{\alpha}$ for all $i \in \mathcal{I}$. Define the $I$-tuple $\hat{\boldsymbol{\alpha}} \equiv(\hat{\alpha}, \ldots, \hat{\alpha})$ and let $N_{i}^{*}(\hat{\boldsymbol{\alpha}}) \equiv \hat{N}^{*} \in(1, \bar{N}), i \in \mathcal{I}$. Also define the $I$-tuple $\hat{\mathbf{N}}^{*} \equiv\left(\hat{N}^{*}, \ldots, \hat{N}^{*}\right)$.

Let us start with a decrease in marginal production costs (e.g., due to the emergence of CAM), implying an increase in $\hat{\alpha}$. According to (8), if $\hat{N}^{*}>1$ (which is presumed here), the equilibrium product range, $\hat{N}^{*}$, is given by $\partial \Pi_{i}\left(\hat{\mathbf{N}}^{*}, \hat{\boldsymbol{\alpha}}\right) / \partial N_{i}=$ 
$C^{\prime}\left(\hat{N}^{*}\right)$. Applying the implicit function theorem to this condition, one obtains

$$
\frac{\partial \hat{N}^{*}}{\partial \hat{\alpha}}=-\frac{I \partial^{2} \prod_{i}\left(\hat{\mathbf{N}}^{*}, \hat{\boldsymbol{\alpha}}\right) / \partial N_{i} \partial \hat{\alpha}}{\partial^{2} \Pi_{i}\left(\hat{\mathbf{N}}^{*}, \hat{\boldsymbol{\alpha}}\right) / \partial N_{i}^{2}+\sum_{j \neq i} \partial^{2} \Pi_{i}\left(\hat{\mathbf{N}}^{*}, \hat{\boldsymbol{\alpha}}\right) / \partial N_{i} \partial N_{j}-C^{\prime \prime}\left(\hat{N}^{*}\right)} .
$$

Using parts (i) and (iv) of Corollary 1, and observing both A2 and $C^{\prime \prime}(\cdot) \geq 0$, $\partial \hat{N}^{*} / \partial \hat{\alpha}>0$ is implied. That is, if intangible asset qualities improve, then product ranges of firms increase. In an analogous way, a downward shift in the marginal sunk cost schedule $C^{\prime}$ (e.g., due to the emergence of CAD) leads to an increase in $\hat{N}^{*}$.

\section{Concluding Remarks}

This paper has analyzed an oligopoly model with asymmetric multiproduct firms, which is consistent with the long-standing empirical regularity that larger firms offer more diversified product lines. The analysis suggests that heterogeneity of enterprises with respect to intangible assets is a driving force behind a positive relationship between firm size, measured by total sales, and product diversification. This result has been derived for the familiar specification of linear demand schedules and differentiated goods under Cournot competition (under weak additional assumptions), by applying a recently developed tool for comparative-static analysis of games with strategic substitutes.

Admittedly, the focus of the present analysis on the number of products as measure of product diversification is quite narrow. For instance, Gollop and Monahan (1991) construct a diversification index which, in addition to the number of products supplied by an enterprise, also accounts for the distribution of sales from these products within a firm and differences in the heterogeneity of products. Applying this index to a large data set of U.S. manufacturing firms and establishments, they find that "[t]he number component is the dominant force" in explaining corporate diversification (p. 327). This gives some justification for focussing the theoretical analysis on the number of products, exogenously fixing the degree of product 
differentiation, and thus, leading to a uniform sales distribution within a firm.

\section{Appendix}

Proof of Proposition 1: First, note that $\pi_{i}=\sum_{k \in \mathcal{N}_{i}}\left(p_{k}-c_{k}\right) x_{k}$ implies

$$
\frac{\partial \pi_{i}}{\partial x_{k}}=p_{k}-c_{k}+\sum_{l \in \mathcal{N}_{i}} \frac{\partial p_{l}}{\partial x_{k}} x_{l}
$$

where $\partial p_{l} / \partial x_{l}=-\beta$ and $\partial p_{l} / \partial x_{k}=-\gamma$ for $l \neq k$, according to demand structure (1). Thus, optimal behavior of firm $i \in \mathcal{I}$ at stage 2 is given by the following set of first-order conditions (presuming an interior solution): $\alpha_{i}-2 \beta x_{k}-\gamma \sum_{l \in \mathcal{K} \backslash\{k\}} x_{l}-$ $\gamma \sum_{l \in \mathcal{N}_{i} \backslash\{k\}} x_{l}=0, k \in \mathcal{N}_{i}$, where $\alpha_{i}=A_{k}-c_{k}$ for all $k \in \mathcal{N}_{i}$ has been used (assumption A1). Adding and subtracting $2 \gamma x_{k}$ implies

$$
\alpha_{i}-2(\beta-\gamma) x_{k}-\gamma Q-\gamma \sum_{l \in \mathcal{N}_{i}} x_{l}=0
$$

where $Q \equiv \sum_{l \in \mathcal{K}} x_{l}$ is total output in the market. Thus, $x_{k}=x_{i}$ for all $k \in \mathcal{N}_{i}$, which implies $\sum_{l \in \mathcal{N}_{i}} x_{l}=N_{i} x_{i}$. Hence, (A.2) can be rewritten as

$$
x_{i}=\frac{\alpha_{i}-\gamma Q}{2(\beta-\gamma)+\gamma N_{i}}
$$

Note that $Q=\sum_{i} N_{i} x_{i}$. Multiplying both sides of (A.3) by $N_{i}$ and summing over all $i \in \mathcal{I}$, one obtains the total output level $\tilde{Q}=\sum_{i} N_{i} \tilde{x}_{i}$ in Cournot-Nash equilibrium, given by

$$
\gamma \tilde{Q}=\frac{\sum_{i} \alpha_{i} \Gamma_{i}}{1+\sum_{i} \Gamma_{i}},
$$

where $\Gamma_{i}=\gamma N_{i} /\left[2(\beta-\gamma)+\gamma N_{i}\right]$. (A.4) implies

$$
\alpha_{i}-\gamma \tilde{Q}=\frac{\Lambda_{i}}{1+\sum_{i} \Gamma_{i}}
$$

where $\Lambda_{i}$ is defined in Proposition 1. Using (A.3) and (A.5) yields (3). ${ }^{14}$

\footnotetext{
${ }^{14}$ Also note from (A.5), and the definitions of both $\Lambda_{i}$ and $\Gamma_{i}$, that $\tilde{Q}$ is decreasing in $N_{i}, i \in \mathcal{I}$, as claimed in footnote 8 .
} 
To obtain (4), first, note that $p_{k}-c_{k}=\alpha_{i}-(\beta-\gamma) x_{k}-\gamma Q$ for all $k \in \mathcal{N}_{i}$, according to (1) and $\alpha_{i}=A_{k}-c_{k}$. Since $\tilde{x}_{k}=\tilde{x}_{i}$ for all $k \in \mathcal{N}_{i},($ A.3) then implies equilibrium price-cost differences (or mark up's, respectively) $\tilde{p}_{k}-c_{k}=\left(\beta-\gamma+\gamma N_{i}\right) \tilde{x}_{i} \equiv M_{i}$ for all $k \in \mathcal{N}_{i}$. Finally, noting that $\tilde{\pi}_{i}=N_{i} \tilde{x}_{i} M_{i}$ confirms (4). This concludes the proof.

Proof of Corollary 1: First, let us write $\sum_{h \in \mathcal{I}} \Gamma_{h}=1+\Phi_{-i}+\Gamma_{i}$, where $\Phi_{-i} \equiv \sum_{h \neq i} \Gamma_{h}$. Thus, using $\Gamma_{i}=\gamma N_{i} /\left[2(\beta-\gamma)+\gamma N_{i}\right]$, we have

$$
\tilde{x}_{i}=\frac{\Lambda_{i}}{\left(1+\Phi_{-i}\right)\left(2(\beta-\gamma)+\gamma N_{i}\right)+\gamma N_{i}}
$$

according to (3). By substituting (A.6) into (4), we obtain

$$
\tilde{\pi}_{i}=\frac{N_{i}\left(\beta-\gamma+\gamma N_{i}\right) \Lambda_{i}^{2}}{\left[\left(1+\Phi_{-i}\right)\left(2(\beta-\gamma)+\gamma N_{i}\right)+\gamma N_{i}\right]^{2}} .
$$

Very tedious derivations reveal that

$$
\frac{\partial \tilde{\pi}_{i}}{\partial N_{i}}=\frac{(\beta-\gamma)\left[2\left(\beta-\gamma+\gamma N_{i}\right)+\left(2(\beta-\gamma)+3 \gamma N_{i}\right) \Phi_{-i}\right] \Lambda_{i}^{2}}{\left[\left(1+\Phi_{-i}\right)\left(2(\beta-\gamma)+\gamma N_{i}\right)+\gamma N_{i}\right]^{3}}>0
$$

and

$$
\begin{aligned}
\frac{\partial^{2} \tilde{\pi}_{i}}{\partial N_{i}^{2}=} & \frac{-2 \gamma(\beta-\gamma) \Lambda_{i}^{2}}{\left[\left(1+\Phi_{-i}\right)\left(2(\beta-\gamma)+\gamma N_{i}\right)+\gamma N_{i}\right]^{4}} \times \\
& {\left[\beta-\gamma+\gamma N_{i}+\left(\beta-\gamma+5 \gamma N_{i}\right) \Phi_{-i}+3 \gamma N_{i} \Phi_{-i}^{2}\right]<0, }
\end{aligned}
$$

respectively. Moreover, for $j \neq i$,

$$
\frac{\partial \tilde{\pi}_{i}}{\partial N_{j}}=\frac{-4 \gamma(\beta-\gamma) N_{i}\left(\beta-\gamma+\gamma N_{i}\right)\left(2(\beta-\gamma)+\gamma N_{i}\right) \Lambda_{i} \Lambda_{j}}{\left[2(\beta-\gamma)+\gamma N_{j}\right]^{2}\left[\left(1+\Phi_{-i}\right)\left(2(\beta-\gamma)+\gamma N_{i}\right)+\gamma N_{i}\right]^{3}}<0,
$$

and

$$
\begin{aligned}
& \frac{\partial^{2} \tilde{\pi}_{i}}{\partial N_{i} \partial N_{j}}=-\frac{4 \gamma(\beta-\gamma)^{2} \Lambda_{i}}{\left[\left(1+\Phi_{-i}\right)\left(2(\beta-\gamma)+\gamma N_{i}\right)+\gamma N_{i}\right]^{4}\left[2(\beta-\gamma)+\gamma N_{j}\right]^{2}} \times \\
& \left\{\left(\alpha_{i}-\alpha_{j}\right)\left[2\left(\beta-\gamma+\gamma N_{i}\right)+\left(2(\beta-\gamma)+3 \gamma N_{i}\right) \Phi_{-i}\right] \times\right. \\
& {\left[2\left(\beta-\gamma+\gamma N_{i}\right)+\left(2(\beta-\gamma)+\gamma N_{i}\right) \Phi_{-i}\right]-} \\
& \left.\Lambda_{i}\left[\left(2(\beta-\gamma)+\gamma N_{i}\right)\left(2(\beta-\gamma)+3 \gamma N_{i}\right) \Phi_{-i}+4(\beta-\gamma)\left(\beta-\gamma+\gamma N_{i}\right)\right]\right\} \text {, }
\end{aligned}
$$


respectively. (A.8) and (A.9) confirm part (i) of Corollary 1 and (A.10) confirms part (ii), respectively (recall that $\Lambda_{i}, \Lambda_{j}>0$ in interior equilibrium). Moreover, note that for all $i, j \in \mathcal{I}, j \neq i, \partial \Lambda_{i} / \partial \alpha_{i}>0$ and $\partial \Lambda_{i} / \partial \alpha_{j}<0$ (recall $\Lambda_{i}=$ $\left.\alpha_{i}\left(1+\sum_{j \neq i} \Gamma_{j}\right)-\sum_{j \neq i} \alpha_{j} \Gamma_{j}\right)$. Thus, (A.7) and (A.8) also confirm parts (iii) and (iv), respectively. Part (v) follows from (A.11). This concludes the proof.

Remark 1. Full derivations of (A.8)-(A.11) can be found in supplementary material to this paper, which is available from the author upon request. There, it is also shown that in order to obtain $\partial^{2} \tilde{\pi}_{i} / \partial N_{i} \partial N_{j}>0, j \neq i$, it is necessary that both $\alpha_{i}>\alpha_{j}$ and $\Phi_{-i}>2(\beta-\gamma) /\left[2(\beta-\gamma)+\gamma N_{i}\right]$ simultaneously hold. Thus, as claimed in the main text, even if firms are very heterogenous, assumption A2 may still be fulfilled. $\Phi_{-i} \leq 2(\beta-\gamma) /\left[2(\beta-\gamma)+\gamma N_{i}\right]$ is a sufficient condition for A2 to hold for all configurations $\boldsymbol{\alpha}$.

Proof of Proposition 2: Existence of equilibrium is proven by applying the following classical existence result.

Lemma A.1. (Debreu, 1952). Let $S_{i} \subseteq \mathbb{R}^{m}$ denote the the set of feasible strategies of player $i \in \mathcal{I}$, with a typical element $s_{i}$. Moreover, let $U_{i}: \times_{i} S_{i} \rightarrow \mathbb{R}$ be the payoff function of player $i$. If, for all $i \in \mathcal{I}, S_{i}$ is non-empty, compact and convex and $U_{i}$ is continuous in $\left(s_{1}, s_{2}, \ldots, s_{I}\right)$ as well as quasiconcave in $s_{i}$, the game $\left\{\left(S_{i}, U_{i}\right), i \in \mathcal{I}\right\}$ possesses a pure-strategy Nash equilibrium.

First, note that strategy sets $[1, \bar{N}]$ for the firms' choice at stage 1 (i.e., in maximization problem (7)), are nonempty, compact and convex subsets of $\mathbb{R}$. Second, note that objective functions of firms in $(7), \Psi_{i}(\mathbf{N}, \boldsymbol{\alpha})$, are continuous in $\left(N_{1}, N_{2}, \ldots, N_{I}\right)$. Third, according to part (i) of Corollary 1 and the convexity of $C(\cdot), \Psi_{i}(\mathbf{N}, \boldsymbol{\alpha})=\Pi_{i}(\mathbf{N}, \boldsymbol{\alpha})-C\left(N_{i}\right)$ is strictly concave in $N_{i}$ (and, thus, quasiconcave in $N_{i}$ ). Applying Lemma A.1, this proves existence of a Nash equilibrium for the firms' decision of product ranges. Existence of equilibrium for the entire two-stage game is directly implied. 
Proof of Proposition 5: Define $\Gamma_{i}^{*} \equiv \gamma N_{i} /\left[2(\beta-\gamma)+\gamma N_{i}\right]$ and

$$
\Lambda_{i}^{*} \equiv \alpha_{i}\left(1+\sum_{j \neq i} \Gamma_{j}^{*}\right)-\sum_{j \neq i} \alpha_{j} \Gamma_{j}^{*}
$$

$i \in \mathcal{I}$. Thus, one can write

$$
D_{i}^{*}(\boldsymbol{\alpha})=N_{i}^{*} X_{i}(\mathbf{N}, \boldsymbol{\alpha})=\frac{N_{i}^{*} \Lambda_{i}^{*}}{\left(1+\sum_{i} \Gamma_{i}^{*}\right)\left[2(\beta-\gamma)+\gamma N_{i}^{*}\right]},
$$

according to (3). Hence, we have $D_{i}^{*}(\boldsymbol{\alpha})>D_{j}^{*}(\boldsymbol{\alpha})$ if and only if

$$
\frac{N_{i}^{*} \Lambda_{i}^{*}}{2(\beta-\gamma)+\gamma N_{i}^{*}}>\frac{N_{j}^{*} \Lambda_{j}^{*}}{2(\beta-\gamma)+\gamma N_{j}^{*}} .
$$

Recall from Proposition 4 that $N_{i}^{*}>N_{j}^{*}$ if $\alpha_{i}>\alpha_{j}$. Thus, using (A.14), Proposition 5 is confirmed if, for instance, $\alpha_{i}>\alpha_{j}$ implies $\Lambda_{i}^{*}>\Lambda_{j}^{*}$. To see that this is indeed the case, first, rewrite (A.12) as

$$
\Lambda_{i}^{*}=\alpha_{i}\left(1+\sum_{h \neq i, j} \Gamma_{h}^{*}\right)+\left(\alpha_{i}-\alpha_{j}\right) \Gamma_{j}^{*}-\sum_{h \neq i, j} \alpha_{h} \Gamma_{h}^{*},
$$

$i, j \in \mathcal{I}$. (A.15) then implies that

$$
\begin{aligned}
\Lambda_{i}^{*}-\Lambda_{j}^{*} & =\left(\alpha_{i}-\alpha_{j}\right)\left(1+\sum_{h \neq i, j} \Gamma_{h}^{*}\right)+\left(\alpha_{i}-\alpha_{j}\right) \Gamma_{j}^{*}-\left(\alpha_{i}-\alpha_{j}\right) \Gamma_{i}^{*} \\
& =\left(\alpha_{i}-\alpha_{j}\right)\left(1+\sum_{i \in \mathcal{I}} \Gamma_{i}^{*}\right),
\end{aligned}
$$

i.e., $\Lambda_{i}^{*}>\Lambda_{j}^{*}$ if $\alpha_{i}>\alpha_{j}$. This concludes the proof.

\section{References}

Amey, L.R. (1964). Diversified Manufacturing Businesses, Journal of the Royal Statistical Society 27, series A, part 2.

Anderson, Simon P. and André de Palma (1992). Multi-Product Firms: A Nested Logit Approach, Journal of Industrial Economics 40 (3), 261-276.

Anderson, Simon P., André de Palma and Jacques-Francois Thisse (1992). Discrete Choice Theory of Product Differentiation, Cambridge, MIT Press. 
Athey, Susan and Armin Schmutzler (2001). Investment and Market Dominance, RAND Journal of Economics 32 (1), 1-26.

Aw, Bee-Yan and Geeta Batra (1998). Firm Size and the Pattern of Diversification, International Journal of Industrial Organization 16, 313-331.

Aydemir, Zava and Armin Schmutzler (2002). Acquisitions versus Entry: The Evolution of Concentration, University of Zurich, Socioeconomic Institute, Working Paper No. 208.

Baily, Martin N., Charles Hulten, David Campbell, Timothy Bresnahan, and Richard E. Caves (1992). The Distribution of Productivity in Manufacturing Plants, Brookings Papers of Economic Activity 0, Microeconomics, 187-249.

Bartelsman, Eric J. and Mark Domes (2000). Understanding Productivity: Lessons from Longitudinal Microdata, Journal of Economic Literature 38, 569-594.

Baumol, William J. (1977). On the Proper Test for Natural Oligopoly in a Multiproduct Industry, American Economic Review 67 (5), 809-822.

Caves, Richard E. (1971). International Cooperations: The Industrial Economics of Foreign Investment, Economica 38, 1-27.

Debreu, Gérard (1952). A Social Equilibrium Existence Theorem, Proceedings of the National Academy of Sciences 38 (10), 886-893.

Dixit, Avinash (1986). Comparative Statics for Oligopoly, International Economic Review 27 (1), 107-22.

Gollop, Frank M. and James L. Monahan (1991). A Generalized Index of Diversification: Trends in U.S. Manufacturing, Review of Economics and Statistics 73 (2), 318-330.

Gorecki, Paul K. (1975). An Inter-Industry Analysis of Diversification in the U.K. Manufacturing Sector, Journal of Industrial Economics 24 (2), 131-146.

Goto, Akira (1981). Statistical Evidence on the Diversification of Japanese Large Firms, Journal of Industrial Economics 29 (3), 271-278.

Markusen, James R. (2002). Multinational Firms and the Theory of International Trade, Cambridge, MIT Press. 
Milgrom, Paul and John Roberts (1990). The Economics of Modern Manufacturing: Technology, Strategy, and Organization, American Economic Review 80 (3), $511-528$.

Montgomery, Cynthia A. (1994). Corporate Diversification, Journal of Economic Perspectives 8 (3), 163-178.

Ottaviano, Gianmarco I.P. and Jacques-Francois Thisse (1999). Monopolistic Competition, Multiproduct Firms and Optimum Product Diversity, CORE Discussion Paper No. 9919.

Raubitschek, Ruth S. (1987). A Model of Product Proliferation with Multiproduct Firms, Journal of Industrial Economics 35 (3), 269-279.

Roberts, Mark J. and Dylan Supina (2000). Output Price and Markup Dispersion in Producer Micro Data: The Roles of Producer Heterogeneity and Noise, in: Baye, M. (Ed.), Advances in Applied Microeconomics, Vol. 9, Industrial Organization (JAI Press).

Shaked, Avner and John Sutton (1990). Multiproduct Firms and Market Structure, RAND Journal of Economics 21 (1), 45-62.

Sutton, John (1998). Technology and Market Structure, Cambridge, MIT Press.

Takayama, Akira (1985). Mathematical Economics, 2nd edition, Cambridge, Cambridge University Press.

Utton, M.A. (1977). Large Firm Diversification in British Manufacturing Industry, Economic Journal 87, 96-113.

Vives, Xavier (1999). Oligopoly Pricing: Old Ideas and New Tools, Cambridge, MIT Press. 


\section{CESifo Working Paper Series}

(for full list see www.cesifo.de)

983 Syed M. Ahsan and Panagiotis Tsigaris, Choice of Tax Base Revisited: Cash Flow vs. Prepayment Approaches to Consumption Taxation, July 2003

984 Campbell Leith and Jim Malley, A Sectoral Analysis of Price-Setting Behavior in US Manufacturing Industries, July 2003

985 Hyun Park and Apostolis Philippopoulos, Choosing Club Membership under Tax Competition and Free Riding, July 2003

986 Federico Etro, Globalization and Political Geography, July 2003

987 Dan Ariely, Axel Ockenfels and Alvin E. Roth, An Experimental Analysis of Ending Rules in Internet Auctions, July 2003

988 Paola Conconi and Carlo Perroni, Self-Enforcing International Agreements and Domestic Policy Credibility, July 2003

989 Charles B. Blankart and Christian Kirchner, The Deadlock of the EU Budget: An Economic Analysis of Ways In and Ways Out, July 2003

990 M. Hasham Pesaran and Allan Timmermann, Small Sample Properties of Forecasts from Autoregressive Models under Structural Breaks, July 2003

991 Hyun Park, Apostolis Philippopoulos and Vangelis Vassilatos, On the Optimal Size of Public Sector under Rent-Seeking competition from State Coffers, July 2003

992 Axel Ockenfels and Alvin E. Roth, Late and Multiple Bidding in Second Price Internet Auctions: Theory and Evidence Concerning Different Rules for Ending an Auction, July 2003

993 Pierre Salmon, The Assignment of Powers in an Open-ended European Union, July 2003

994 Louis N. Christofides and Chen Peng, Contract Duration and Indexation in a Period of Real and Nominal Uncertainty, July 2003

995 M. Hashem Pesaran, Til Schuermann, Björn-Jakob Treutler, and Scott M. Weiner, Macroeconomic Dynamics and Credit Risk: A Global Perspective, July 2003

996 Massimo Bordignon and Sandro Brusco, On Enhanced Cooperation, July 2003

997 David F. Bradford, Addressing the Transfer-Pricing Problem in an Origin-Basis X Tax, July 2003 
998 Daniel Gros, Who Needs Foreign Banks?, July 2003

999 Wolfram Merzyn and Heinrich W. Ursprung, Voter Support for Privatizing Education: Evidence on Self-Interest and Ideology, July 2003

1000 Jo Thori Lind, Fractionalization and the Size of Government, July 2003

1001 Daniel Friedman and Donald Wittman, Litigation with Symmetric Bargaining and TwoSided Incomplete Information, July 2003

1002 Matthew Clarke and Sardar M. N. Islam, Health Adjusted GDP (HAGDP) Measures of the Relationship Between Economic Growth, Health Outcomes and Social Welfare, July 2003

1003 Volker Grossmann, Contest for Attention in a Quality-Ladder Model of Endogenous Growth, August 2003

1004 Marcel Gérard and Joan Martens Weiner, Cross-Border Loss Offset and Formulary Apportionment: How do they affect multijurisdictional firm investment spending and interjurisdictional tax competition ?, August 2003

1005 Burkhard Heer, Nonsuperneutrality of Money in the Sidrauski Model with Heterogeous Agents, August 2003

1006 V. Anton Muscatelli, Piergiovanna Natale, and Patrizio Tirelli, A Simple and Flexible Alternative to the Stability and Growth Pact Deficit Ceilings. Is it at hand?, August 2003

1007 Reto Foellmi and Josef Zweimüller, Inequality and Economic Growth: European Versus U.S. Experiences, August 2003

1008 James S. Costain and Michael Reiter, Business Cycles, Unemployment Insurance, and the Calibration of Matching Models, August 2003

1009 Marco Runkel, Optimal Contest Design when the Designer's Payoff Depends on Competitive Balance, August 2003

1010 Donald O. Parsons, Torben Tranaes and Helene Bie Lilleør, Voluntary Public Unemployment Insurance, August 2003

1011 Rüdiger Pethig and Andreas Wagener, Profit Tax Competition and Formula Apportionment, August 2003

1012 Johan Willner, Privatisation and Public Ownership in Finland, August 2003

1013 Seppo Kari and Jouko Ylä-Liedenpohja, Taxation and Valuation of International Real Investments, August 2003

1014 James Heckman, Rosa Matzkin and Lars Nesheim, Simulation and Estimation of Hedonic Models, August 2003 
1015 Biswa N. Bhattacharyay, Towards a Macro-Prudential Leading Indicators Framework for Monitoring Financial Vulnerability, August 2003

1016 J. Stephen Ferris and Stanley L. Winer, Searching for Keynes: With Application to Canada, 1870-2000, August 2003

1017 Massimo Bordignon, Luca Colombo and Umberto Galmarini, Fiscal Federalism and Endogenous Lobbies’ Formation, August 2003

1018 Annette Alstadsæter, The Dual Income Tax and Firms’ Income Shifting through the Choice of Organizational Form and Real Capital Investments, August 2003

1019 Peter Fredriksson and Bertil Holmlund, Optimal Unemployment Insurance Design: Time Limits, Monitoring, or Workfare?, August 2003

1020 Kashif S. Mansori, Following in their Footsteps: Comparing Interest Parity Conditions in Central European Economies to the Euro Countries, August 2003

1021 Christoph Borgmann and Matthias Heidler, Demographics and Volatile Social Security Wealth: Political Risks of Benefit Rule Changes in Germany, August 2003

1022 Kjell Erik Lommerud, Bjørn Sandvik and Odd Rune Staume, Good Jobs, Bad Jobs and Redistribution, August 2003

1023 Patrick Karl O’Brien, The Governance of Globalization: The Political Economy of Anglo-American Hegemony, 1793-2003, September 2003

1024 Antonio Ciccone and Giovanni Peri, Skills' Substitutability and Technological Progress: U.S. States 1950-1990, September 2003

1025 Bjørn Sandvik, Optimal Taxation and Normalisations, September 2003

1026 Massimo Bordignon and Gilberto Turati, Bailing Out Expectations and Health Expenditure in Italy, September 2003

1027 José A. Herce, Namkee Ahn, Ricard Génova, and Joaquín Pereira, Bio-Demographic and Health Aspects of Ageing in the EU, September 2003

1028 John Komlos and Marieluise Baur, From the Tallest to (One of) the Fattest: The Enigmatic Fate of the American Population in the $20^{\text {th }}$ Century, September 2003

1029 Stefan Napel and Mika Widgrén, Bargaining and Distribution of Power in the EU's Conciliation Committee, September 2003

1030 Kai Li and Dale J. Poirier, Relationship Between Maternal Behavior During Pregnancy, Birth Outcome, and Early Childhood Development: An Exploratory Study, September 2003

1031 Ivar Ekeland, James J. Heckman, and Lars Nesheim, Identifcation and Estimation of Hedonic Models, September 2003 
1032 Kjetil Bjorvatn and Alexander W. Cappelen, Decentralization and the Fate of Minorities, September 2003

1033 Lars-Erik Borge and Jørn Rattsø, The Relationships Between Costs and User Charges: The Case of a Norwegian Utility Service, September 2003

1034 Maureen Were and Nancy N. Nafula, An Assessment of the Impact of HIV/AIDS on Economic Growth: The Case of Kenya, September 2003

1035 A. Lans Bovenberg, Tax Policy and Labor Market Performance, September 2003

1036 Peter Birch Sørensen, Neutral Taxation of Shareholder Income: A Norwegian Tax Reform Proposal, September 2003

1037 Roberta Dessi and Sheilagh Ogilvie, Social Capital and Collusion: The Case of Merchant Guilds, September 2003

1038 Alessandra Casarico and Carlo Devillanova, Capital-skill Complementarity and the Redistributive Effects of Social Security Reform, September 2003

1039 Assaf Razin and Efraim Sadka, Privatizing Social Security Under Balanced-Budget Constraints: A Political-Economy Approach, September 2003

1040 Michele Moretto, Paolo M. Panteghini, and Carlo Scarpa, Investment Size and Firm’s Value under Profit Sharing Regulation, September 2003

1041 A. Lans Bovenberg and Peter Birch Sørensen, Improving the Equity-Efficiency Tradeoff: Mandatory Savings Accounts for Social Insurance, September 2003

1042 Bas van Aarle, Harry Garretsen, and Florence Huart, Transatlantic Monetary and Fiscal Policy Interaction, September 2003

1043 Jerome L. Stein, Stochastic Optimal Control Modeling of Debt Crises, September 2003

1044 Thomas Stratmann, Tainted Money? Contribution Limits and the Effectiveness of Campaign Spending, September 2003

1045 Marianna Grimaldi and Paul De Grauwe, Bubbling and Crashing Exchange Rates, September 2003

1046 Assar Lindbeck and Dennis J. Snower, The Firm as a Pool of Factor Complementarities, September 2003

1047 Volker Grossmann, Firm Size and Diversification: Asymmetric Multiproduct Firms under Cournot Competition, September 2003 